\title{
A imitação do corpo no Auto da barca do inferno
}

\author{
Jaqueson Luiz da SILVA ${ }^{1}$
}

UNIANCHIETA

Este é um pequeno esboço, a partir deste célebre auto de Gil Vicente do início do XVI, Auto da barca do inferno, de algumas questões que se pretendem ampliar em estudo de maior proporção com textos ibéricos do XVI e XVII: a possibilidade de se entrever na tessitura da poesia (comédia e tragédia, quiçá da épica, ou mesmo em outros textos retórico-poéticos), a partir da formulação da memória e da ação, os lugares daquele que pronuncia, lê, ouve, escreve, interpreta: o poeta, o orador, o ator, o espectador, o leitor. Seria esta a perspectiva, o que por ora apenas em hipótese refletimos, que dá a ver o corpo em sua realidade textual, proposta em estudos que lê a poética e a retórica antigas redimensionadas em uma postura crítica e teórica da interpretação como a que se vê nos estudos de Roland Barthes, Michel Foucault e Paul Ricoeur, por exemplo. Diferente do que brevemente aponta Ernst Curtius com as metáforas das partes do corpo nomeadas textualmente em autores do cristianismo primitivo (1996, p.188-190), bem como, atendo-se a um interessante conjunto lexical que dá conta de supostas contextualizações do espetáculo dos autos vicentinos, Maria José Palla (1997, VI, p.137-177).

A busca deste corpo e desta ação, é o que se supõe, vai dar-se mais no mito poético do que nas chamadas rubricas ou inscrições e direções para o espetáculo ${ }^{2}$ que indicam, marcam e demarcam entradas e saídas, posições, feições, gestos, tonalidades da vOz e dos afetos. São estes mesmos elementos que buscamos, mas entendemos

1 Doutor em Teoria e História Literário pelo IEL/UNICAMP. Professor de Literatura Portuguesa e Teoria Literária no UNIANCHIETA/Jundiaí-SP.

2 “Quanto ao espetáculo cênico, decerto que é o mais emocionante, mas também é o menos artístico e menos próprio da poesia. $\mathrm{Na}$ verdade, mesmo sem representação e sem atores, pode a tragédia manifestar seus efeitos; além disso, a realização de um bom espetáculo mais depende do cenógrafo que do poeta" (Poética, 1450 b, 39). 
que a rubrica evidencia a sombra deste mesmo corpo que já esteve, mas não está mais lá, ou poderia estar, então, ainda não o corpo; entendemos que o próprio corpo do poeta, que também propõe o do ator e do espectador, está ele mesmo nas partes do próprio fazer poético: a memória e a ação, o corpo mesmo da poesia, o mito tecido, a mímesis e se quisermos mais pensado modernamente como a dramaturgia. É bem provável que estas marcações, que não se desconsidera constituir o texto poético, sejam postas em cena muitas vezes à revelia do próprio texto, ou melhor, são postas em maior relevo que o próprio corpo poético, quando na verdade parecem ser mais dirigidas ao espetáculo que ao ator. Pensemos como o auto de Gil Vicente pode ser interpretado segundo esta orientação.

Quando o poeta diz "Vem o fidalgo e, chegando ao batel infernal diz", os verbos "vir", "chegar" e "dizer" nada ou quase nada me dizem sobre este corpo de fidalgo, a não ser que vai se apresentar, ou seja, ainda vai estar, é um devir, um fantasma ainda, um lugar ainda a ser buscado na memória de quem age e de quem vê, ou de quem o escreveu ou ainda de quem lê.

Possivelmente, o argumento do auto, no sentido ciceroniano definido no De Inventione (XIX, 27), ficção, mais especificamente um evento criado, mas que poderia acontecer, ou seja, possível, verossímil, diferente da fábula, e da história, que também não estão nem entre a verdade, nem entre o verossímil, ainda como uma das formas de narração das causas judiciárias e deliberativas que como recurso dispõe ao orador meios de se dirigir à comprovação, é de onde se pode partir, aliando matéria e cena, para a demonstração da questão como proposta de leitura desse teatro. $\mathrm{O}$ argumento é ele mesmo fantasma e sombra do mito poético que está por ser feito sobre algumas vidas, ironicamente elas mesmas antes fantasmas que pela possibilidade da ficção ganham corpo cênico, cômico, poético à medida que o poeta se lhes apresentam: 
Representar na obra seguinte uma prefiguração sobre a rigorosa acusação que os inimigos fazem a todas as almas bumanas, no ponto que por morte de seus terrestres corpos se partem. E por tratar desta matéria põe o autor por figura que no dito momento elas chegam a um profundo braço de mar, onde estão dois batéis: um deles passa para a Glória, outro para o Purgatório. É repartida em três partes: de cada embarcação, uma cena. Esta primeira é da viagem do Inferno. (grifos meus)

Não desconsiderando, porém nos isentando aqui de discutir, uma pertinente hipótese de imitação de A Divina Comédia, dados os aspectos didáticos e de moralidade sempre atribuídos ao auto (RECKERT, 1977, p.69), os termos grifados é que nos prendem ao argumento, salientando que representar, como sinônimo de imitação, estaria mais distante do sentido platônico ${ }^{3}$ que do aristotélico, com o qual pensamos, quer dizer, o mito como organismo vivente (Poética, 1459 a, 147) e não como imagem degenerada da idea, pois "enquanto a mimese platônica afasta a obra de arte dos graus do modelo ideal que é seu fundamento último, a mimese de Aristóteles tem só um espaço de desenvolvimento: o fazer humano, as artes de composição" (RICOEUR, 1995, p.60).

Não há outro modo de "encenar" o "corpo terrestre" morto senão "prefigurado" como "alma humana", ou seja, como uma figura, imagem, alegoria que se anuncia. A alegoria, como criação poética ou como lugar retórico, compreende a noção de transporte, ou seja, uma forma que se translada em outra, a fim de se efetuar em um sentido outro. Logo, sua associação com o efeito metafórico do "pôr diante dos olhos" preconizado pela retórica aristotélica (L. III, 10, 1410 b). Dessa maneira, como criação poética ou retórica e como leitura e interpretação, repercute a verossimilhança do texto. $\mathrm{Na}$ exegese cristã, por exemplo, é o meio pelo qual, maiormente, compreender-se-ia as

\footnotetext{
${ }^{3}$ Encontrado posteriormente nas questões dramáticas, principalmente no XIX, via leitura do Prefácio de Cromwell de Victor Hugo, não especificamente em seu texto, no sentido de formular o texto cênico como um reflexo da realidade, menos que reflexão, menos que ele mesmo uma proposta de realidade e de experiência criadora viva.
} 
intervenções da Providência Divina no tempo e na história. $\mathrm{Na}$ poesia, a ordenação do mito no caso de uma tragédia, de uma épica ou de uma comédia: as ações, pensamento e caracteres das personagens ${ }^{4}$. Neste sentido, é sempre um diante dos olhos que está em cena, a matéria que o autor põe em figura (eikon): os corpos estão em cena, porque já estão prefigurados e figurados no mito poético. Deste ponto de vista, são mais do que sombras de uma idea. Podem ser pensados como a própria sombra, a própria alegoria, como sombra de nada, tão somente ela matéria feita em poesia, por isso corpo.

Este entrar e sair pode bem assemelhar-se ao procedimento metafórico (phora) cuja base retórica e poética está na lexis, no nome que, ausente, precisa tomar emprestado um outro nome para fazer sentido (Idem; Poética, 1457b), o que faz pensar que o que se apresenta nunca é próprio senão um contínuo deslocamento metafórico, figurativo, alegórico (RICOUER, 2000, p. 31); enfim “a função mimética da narrativa coloca um problema exatamente paralelo ao da referência metafórica. É até mesmo apenas uma aplicação particular desta última à esfera do agir humano" (RICOUER, 1995).

Se pensarmos assim, as personagens desse auto, como essa figura que transita, têm seu sentido alegórico superado para além do aspecto meramente teológico e moral e passa a ser vista e demonstrada também em seu movimento poético à medida que são nomeados e deslocados no mito pelo fazer do poeta, com a elocução na conformação do pensamento das personagens "que é aquilo em que a pessoa demonstra que algo é ou não é, ou enuncia uma sentença geral", revelando assim o seu caráter que é "o que revela certa decisão ou, em caso de dúvida, o fim preferido ou evitado; por isso não têm caráter os discursos do indivíduo em que, de qualquer

${ }^{4}$ Para estudos sobre a criação e interpretação alegórica ou figural nos aspectos pontuados aqui cf. AUERBACH (1997), HANSEN (1987), RICOEUR (2000).

Jaqueson Luiz da Silva 
modo, se não revele o fim para que tende ou o qual repele" (Poética, 1450b):

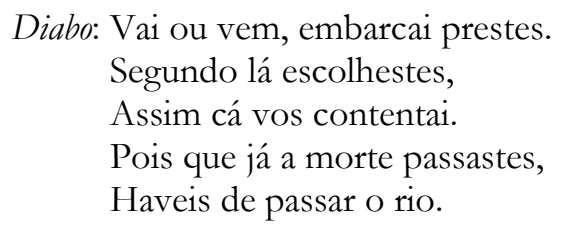

No trecho acima se evidencia o emprego das palavras do diabo no fim de apresentar o sentido de morte deslocado para o sentido de "vai ou vem", "lá", "cá" e no aspecto proverbial de "pois que já a morte passastes,/ haveis de passar o rio”. Porque fala, ação, pensamento, sentença, elocução e metáfora, apresenta a personagem e indica o deslocamento poético do auto.

Segundo a descrição de Paul Teyssier (1982, p.109), os autos de Gil Vicente não possuiriam um enredo - aristotelicamente designado de mytho (1450 a, 30) -; seguiriam, apenas, uma composição paratática, cuja apresentação dos caracteres conformariam esquetes, pequenos quadros, num sentido propriamente farsesco. Entretanto, o Auto da barca do inferno enquanto imitação de ações pode ser pensado como poesia de caracteres cujo mito poético desloca-se pelo movimento alegórico das práticas das personagens. Aproximamo-nos um pouco das análises estruturalistas feitas por Stephen Reckert, cujo esquema póièma (ato), páthèma (sofrimento) e máthèma (percepção) atribuí ao auto um caráter mais hipotático na reflexão ritmo/ritual, principalmente da leitura que faz do Parvo enquanto figura paradoxa (1977, cap. II, p. 61-87). Todavia avançaremos a discussão para além das noções simbólicas e arquetípicas, que seriam em outra esfera teórica a mesma vertente da análise do auto em sua possibilidade de alegoria moral apenas. Talvez estejamos mais perto do que propõe Michel Foucault a respeito da linguagem e interpretação no século XVI, não que seja nosso intuito comprová-lo, quando as similitudes e assinalações (convenientia, aemulatio, analogia e simpatia) estavam na base 
de uma hermenêutica da sintaxe das palavras e das coisas (2007, p. 3541):

No século XVI, a linguagem real não é um conjunto de signos independentes, uniforme e liso, em que as coisas viriam refletir-se como num espelho, para aí enunciar, uma a uma, sua verdade singular. É antes coisa opaca, misteriosa, cerrada sobre si mesma, massa fragmentada e ponto por ponto enigmática, que se mistura aqui e ali com as figuras do mundo e se imbrica com elas: tanto e tão bem que, todas juntas, elas formam uma rede de marcas, em que cada uma pode desempenhar, e desempenha de fato, em relação a todas as outras o papel de conteúdo ou de signo, de segredo ou de indicação (FOUCAULT, 2007, p.47).

Da leitura da Poética, veem-se que as três principais formas poéticas são imitações de ações, ou seja, formam-se pelo mito (a matéria e o fazer), contudo uma por narrativa, outra por ação de atores e outra por caracteres. A comédia contém o mito, a imitação de ações, o caráter e o pensamento; apenas, pode-se supor tenha como finalidade imitar homens piores, por isso faz subordinarem-se o mito e o pensamento ao caráter, "o que nos faz dizer das personagens que elas têm tal ou tal qualidade". Pode-se deduzir que seguindo as finalidades, assim, a épica, ao mito, “a composição dos atos”, e a tragédia, ao pensamento: "tudo quanto digam as personagens para demonstrar o que quer que seja ou para manifestar sua decisão" (1450 a, 30).

Compreende-se perfeitamente a distinção que Aristóteles estabelece entre tragédia e comédia, em que uma é imitação de ação e a outra de caracteres, o que não exclui desta a possibilidade de possuir um mito poético e isto parece bem visível ao menos neste auto. Em alguns momentos, percebe-se pelo pensamento da personagem o anúncio da rubrica e, logo em seguida, a entrada do pensamento da personagem anunciada, como na primeira cena em que o diabo recebe seu primeiro passageiro: 


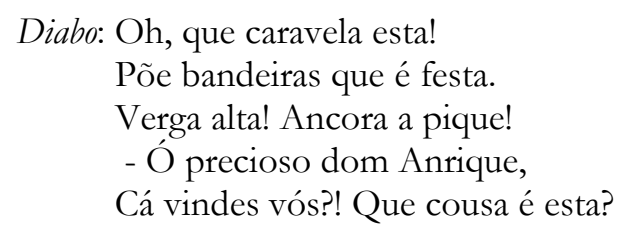

Em outros momentos, a fala da personagem indica outras que estão fora de cena, conduzindo a personagem com quem fala e o espectador a criar "diante dos olhos" a sua presença com os tópicos que organizam a memória do que se viu ou do que se conhece. O poeta dessa maneira conduz o ator e o espectador não apenas pelas alegorias que cria, mas simultaneamente, ao desdobrar do mito, permite que a mimesis, ou seja, o fazer da poesia, atravesse sua memória, a do ator e a do espectador e o tecer do mito compõe-se como um só corpo, ou em termos mais presentes, coletivamente.

\section{Diabo: Quem reze sempre por ti!... \\ Hi! Hi! Hi! Hi! Hi! Hi! Hi!... \\ E tu viveste a teu prazer \\ Cuidando cá guarecer \\ Porque rezem lá por ti?}

O caráter a que remete a fala do diabo é justamente de uma terceira pessoa plural, um grupo que chora a morte de alguém. É um lugar-comum, um tópico, uma sentença, retoricamente, um caráter, poeticamente. Mesmo no século XVI, a sentença e os exemplos dos auctores vinculam-se ao exercício mnemônico da formação do poeta e associam-se à composição da imago (eikon) (CURTIUS, 1996, p. 9598). Neste aspecto, a elaboração metafórica vincula-se à da memória.

Importa aqui trazer uma reflexão efetuada por Paul Ricouer com a Poética de Aristóteles em confronto, agora, com as Confissões de Santo Agostinho, na qual existe naquele um desejo de explicação da narrativa a partir da experiência temporal do homem e neste a vontade de explicação do tempo por meio da narrativa memorativa da confissão. Afora as reflexões sobre o tempo que não adentraremos aqui, o que nos interessa do trabalho de Ricouer é a equivalência que 
propõe entre a espera, memória e atenção da distensio e intensio anima das Confissões com o muthos e peripeteia da Poética. Embora Santo Agostinho não estivesse interessado em elaborar conceitos para as artes miméticas, sua concepção filosófica sobre o tempo traz consequências para todo domínio da narrativa, pois se narram as coisas que são consideradas verdadeiras e são preditos os acontecimentos que ocorrem tal como haviam sido antencipados, pois narração implica memória e previsão implica espera. O que se tem é uma elaboração da expectação em que a intenção presente faz passar o futuro para o passado, esgotando o futuro, tornando tudo passado. Se pensarmos a partir do modelo exegético de Santo Agostinho, a história, a narrativa, já estão prontas desde sempre na memória, como prefigurações prontas a se cumprirem no compassar do tempo. Segundo Ricoeur, a reflexão de Santo Agostinho busca conciliar a discordância entre o caos apresentado pelo tempo, como imagem da eternidade, diante da impressão da memória (1995, p. 2527; p. 38-42). No caso de Aristóteles, ainda segundo Ricoeur, o tecer do mito é a imitação criadora da experiência temporal viva: a concordância da desordem do tempo pela ordenação poética. A memória do espectador é tecida no organismo vivo do mito poético (Idem, p. 55).

A consequência desse pensamento para a leitura de um texto como o de Gil Vicente é a de ver as figuras postas em cena ora como representações estáticas de lugares históricos, cópia, réplica do idêntico, se pudermos dizer, uma espécie de figuração estática e então moralizante; ora, inversamente, como alegorias vivas, em que o reconhecê-las não está somente no que representa a alegoria, mas no deslocamento que o mito obriga a memória a efetuar pelos lugarescomuns, apotegmas, sentenças como imagens impressas na alma (cf. YATES, 2007, p.17-45). A distensio e intensio anima de Agostinho ocorre também em textos ficcionais mesmo que contra isso tenha se debatido (SILVA, 2008, p. 2-4). 
No auto, outro exemplo semelhante ao que antes se apresentou e em que a demonstração passa a ser mais persuasiva, ainda está no colóquio entre o diabo e o fidalgo:

Diabo: Pois, estando tu expirando, Se estava ela requebrando Com outro de menos preço.

Fidal. Dá-me licença, te peço,

Diabo: Que vá ver minha mulher.

E ela, por não te ver, Despenhar-se-á dum cabeço. Quanto ela hoje rezou, Entre seus gritos e gritas, Foi dar graças infinitas A quem na desassombrou.

Aqui o diabo, porque é uma comédia, ironiza e rebaixa a personagem com o contrário do termo "assombrar". Pelo que fica da fala é que o fidalgo agora morto é que vai deixar de assombrar sua mulher. Desassombrado o fidalgo do corpo da outra vida, porque assim como o poeta que sabe o fim do auto, o diabo, como um ordenador do mito, o próprio poeta, ou melhor, uma de suas muitas faces, como acontece na tragédia e na épica (Poética, 1448 a, 19), faz a presença do fidalgo perante a barca infernal mais viva do que nunca. Seu corpo está ali e não no outro lado da morte, a outra vida como deseja:

Fidal. Mas esperai-me aqui

Tornarei à outra vida, Ver minha dama querida Que se quer matar por mi

O diabo, como o poeta, conhece exatamente os caracteres das personagens que entram em cena e, quando deles fala, traz à memória do espectador seja por sentenças, seja pela elaboração de metáforas:

Onzen. Lá me ficam de roldão

Vinte e seis milhões nũa arca.

Diabo. Pois quem onzena tanto abarca

Pitágoras, 500 - vol. 1 - Outubro 2011 
Não lhe deis embarcação.

$\mathrm{Na}$ passagem acima que é o desfecho da tentativa do onzeneiro de tomar assento na barca da glória, o riso está exatamente na palavra "arca", muito própria de quem empresta com usura, e que logo em seguida na fala do diabo ganha um sentido contrário e vil com "abarca" e, imediatamente, o juízo na palavra "embarcação", mais para o inferno que para a glória. O jogo de cena, ao mesmo tempo em que se dá no encadeamento do mito, perpassa a ação das personagens (por que não dizer atores?) e na associação que se dá diante dos olhos do espectador por meio de sua memória, pois “assim também os mitos devem ter uma extensão bem apreensível pela memória" (Poética, 1451 a, 44). Percebe-se que o ritmo estende-se para além da rima e alcança os tópicos de um raciocínio deliberativo e ético, uma vez que a ação de uma personagem poética pode ser pensada como uma ação ética em que a escolha o leva ao fim da poesia, terror e compaixão na tragédia, riso na comédia. Neste sentido, a personagem age com os lugares que conhece, ou seja, a memória, que são dados pelo poeta no mito e com o qual organiza a memória do espectador, para que também se conduza ao fim desejado. Assim como diz Aristóteles, o mito é vivente exatamente porque se conforma na mímesis (Poética, 1450 b, 22-44; 1451 a, 44-45), na qual se encontram o poeta, o ator e o espectador simultaneamente.

Em outro momento, o mesmo fidalgo em contracena com o onzeneiro traz à memória o lugar da cortesia que supostamente cria graça no interior do mito do auto e diz muito de seu caráter e sua articulação com as outras personagens que se seguem e que, posteriormente, mais intensamente vai ser posto a riso pelo poeta na figura do frade. Vejamos:

Onzen. Santa Joana de Valdês!

Cá é vossa Senhoria?!

Fidal. Dá ao demo a cortesia!

Diabo. Ouvis? Falai vós cortês! 
Vós fidalgo, cuidares!

Que estais em vossa pousada?

Dar-vos-ei tanta pancada

C'um remo que arreneguês!

O fidalgo é cortês ("Para senhor de tal marca/Não há aqui mais cortesia"), no entanto em um tempo em que não se fala mais cortês como seria nos séculos XI e XII, falta percebida na intervenção do diabo que o repreende também por outra ação indecorosa: dizer ao onzeneiro ser cortês sem nunca tê-lo sido. A referência a um tempo de cortesia de que se tem lembrança apenas pelos cancioneiros torna o fidalgo assim como o frade, que veremos em seguida, duas figuras extremamente vituperadas pelo diabo, pelo poeta e pelo espectador, quando arremedam sem decoro algum o trovar. Há aqui um escárnio e nesse ponto o poeta é absolutamente decoroso, pois estabelece as cantigas como lugares da memória do fazer poético ao mesmo tempo em que as imita no interior da comédia, que tudo abrange em seu corpo imperfeito como são igualmente imperfeitos os corpos que imita e de quem o escarnecer de algumas cantigas é modelo. Desse modo temos que poetas, atores e espectadores sabem o que é o trovar, para assim poderem criar corpos que não sabem o que é, então o riso.

A presença do Parvo, o louco, parece ser um contraponto à ação do diabo, como uma outra face da ação do mito, ou seja, uma espécie de peripécia: a mutação dos sucessos no contrário (Poética, 1452 a, 22), trazendo mais para perto dos olhos a inversão das coisas do mundo, ou seja, a vida no inferno como o inverso da vida terrena, ou a vida terrena como se fosse a vida no inferno (CURTIUS, 1996, V. 7, p. 139-144). Enquanto o fidalgo e o onzeneiro, bem como as personagens seguintes, têm seus caracteres apresentados pelas falas do diabo, no caso de Joane, o parvo, há uma fala de si, bem conveniente à falta de juízo: "Eu sô" e "Não sou ninguém", quando se apresenta ao anjo. Lembra-se aqui perfeitamente o momento em que Ulisses diz 
a Polifemo que é Ninguém, ou seja, ausente de eu, de caracteres, ou o contrário de Édipo que age na desventura de saber quem é. Ulisses e Édipo enfrentam o mito da poesia que protagonizam exatamente nestes momentos. Pelos lábios de Polifemo cego, Ulisses tem elementos para contar aos outros os seus próprios feitos, matéria da Odisseia, enquanto Édipo, depois de cego, tem em contra volta as ações que levaram a sua desdita. O Parvo, assim como o Anjo e o Diabo agem como supostas personagens épicas ou trágicas, conhecendo o mito do qual fazem parte, ao contrário das personagens cômicas e, nesse sentido, têm condições, assim como o poeta, de conduzir a ação. Entretanto, provavelmente por se tratar de uma circunstância cristã, nesta tríade, o Diabo recebe, neste momento, um rebaixamento, pois é apresentado em todos seus caracteres pelo Parvo:

Diabo: Ao inferno, entra cá.

Parvo: Ao inferno, ieramá?!

Hiu! Hiu! Barca do cornudo, Pero Vinagre beiçudo,

Rachador de Alverca, huhá!

Sapateiro da Candosa!

Entrecosto de carrapato!

Hiu! Hiu! Caga no sapato, filho da grande aleivosa!

Tua mulher é tinhosa

e há-de parir um sapo chentado no guardanapo!

Neto da cagarrinhosa!

Furta-cebolas! Hiu! Hiu!

'xcomungado nas igrejas!

Burrela, cornudo sejas!

Toma o pão que te caiu, A mulher que te fugiu

Para a Ilha da Madeira!

Ratinho da Giesteira,

O demo que te pariu!

Hiu! Hiu Lanço-te uma pulha

De pica naquela!

Hiu! Hiu! Hiu! Caga na vela, Ó dom Cabeça-de-grulha!

Perna de cigarra velha, 
Caganita de coelha,

Pelourinho da Pampulha,

Rabo de forno de telha

É como se uma aparente sabedoria do Diabo fosse desmascarada pela completa falta de juízo, fazendo com que o Parvo assumisse, ao confirmar as falas daquele, o lugar de dizer a essência das coisas. Depois de dizer "Não sou ninguém”, ao que o Anjo confirma pela "simpleza", o que entendemos a falta de hábito vicioso e assim de caráter cômico, o Parvo recebe o direito de embarcar na glória e desta forma promove a peripécia no auto de uma situação de desdita para a felicidade. Contanto o Anjo, sabedor dos movimentos da ventura, pede ao Parvo que espere um momento para ver se outros seguirão o mesmo caminho.

A entrada do sapateiro, mesmo antes da rubrica, já está anunciada nos vários nomes do diabo, que é uma espécie de memória, enumerados pelo Parvo ("Sapateiro da candosa", "Caga no sapato"); ao mesmo tempo em que apresenta o diabo já em cena, anuncia a personagem que confirma em sua fala as metáforas da sapataria tão próximas das causas da morte do Parvo e dos tantos nomes do Diabo:

Sapat. Ora eu me maravilho Haverdes por grão peguilho Quatro forminhas cagadas Que podem bem ir chentadas Num cantinho desse leito

Do mesmo modo, o Sapateiro, antes da fala anterior que é destinada ao Anjo, ao tentar se justificar perante o Diabo que, pelo fato de vir confessado e frustadamente reconhecer que as muitas missas a que havia assistido de nada o livrariam da funesta embarcação, anuncia a entrada do Frade: "Quantas missas eu ouvi/não me hão elas de prestar?”. Tal pensamento, fala da personagem conforme a Poética, "Gentil padre mundanal" como quer 
o Diabo, ainda "tão namorado", "devoto padre e marido" confirma os efeitos tão pouco gloriosos das missas fúnebres a que fora submetido o defunto sapateiro, uma vez que os frades andam sendo mais cortesãos que sacerdotes dos serviços sagrados. Em seguida, quando da entrada de Brisida Vás, justifica-se a fala esquecida do frade sobre a dama que o acompanha, também porque está a navegar o rio do esquecimento e da morte:

Diabo: Essa dama há de entrar cá?

Frade: Não sei onde embarcarei.

Diabo: Ela é vossa?

Frade. $\quad$ Não sei;

Por minha a trago eu cá.

Diabo: Ela é vossa?

Da entrada do frade em diante, podemos pensar que por conta de uma espécie de reversão e inversão de lugares criada pela presença do Parvo que assume a posição daquele que conduz o mito do auto, ou seja, faz às vezes de poeta, daquele que conhece todos os caracteres mais que o próprio Diabo, assim com o Anjo, como que "maravilha" ou peripécia, o mundo com suas personagens evidencia mais o seu avesso. As personagens vão sendo criadas e se apresentando como que aglomeração das outras que por alí já passaram e desse modo cada vez mais corporificadas, mais acabadas em seus vícios, visivelmente mais corpo.

Percebe-se que essas entradas e saídas das personagens são sombras anunciadas pelo pensamento de outras e que como o efeito da alegoria deslocam-se na efetuação de uma nova forma e que como sombras se estabelecem como presenças cada vez mais perfeitas em direção ao fim do auto como imitação acabada. Neste aspecto, o frade é sacerdote, cortesão e cavaleiro, anunciando os cavaleiros do final em seu jogo de esgrima, música e dança - "Tarararairão, tairararairão" - que é o próprio fazer e 
avançar do mito poético, neste momento do mito, verossimilhança do auto:

Daqui se sai c’uma guia

E um revés da primeira.

Esta é a quinta verdadeira.

- Oh! Quantos daqui feria!

Padre que tal aprendia

No inferno há de haver pingos?!

Ah! Não praza a São Domingos

Com tanta descortesia!

Tornou a tomar a Moça pela mão dizendo:

Prossigamos nossa história (...) [grifos meus].

Brísida Vaz, por sua vez, se pudermos dizer, encerrando a entrada das personagens centrais (ela, mais o Parvo e o Frade) e isso se oporia a uma leitura que não identifica protagonistas neste auto, em seu pensamento esclarece uma pensamento anterior do Parvo, que mostra a aparência em que o frade apresenta-se, diferente de sua essência "Andar, muitieramá!/Furtaste esse trinchão, frade?; enumera o engano que é seu ofício, ou melhor, que seu ofício tem a ver com o engano:

Diabo. Que é o que haveis de embarcar?

Bris. Seicentos virgos postiços

E três arcas de feitiços

Que não podem mais levar.

Três armários de mentir,

E cinco cofres de enleios,

$\mathrm{E}$ alguns furtos alheios,

Assi em jóias de vestir;

Guarda-roupa de encobrir,

Enfim - casa movediça;

Um estrado de cortiça

Com dez coxins de embair.

A mor carrega que é:

Essas moças que vendia.

Daquesta mercadoria.

Em seguida, seu pensamento inverte as aparências e demonstra que as insígnias para ser santo tem-nas os que vivem a vida de santo aparentando não ser, ou melhor, se é preciso ter insígnias, 
marcas de açoite e tanto mais tormentos para merecer o paraíso, não é preciso querer ser santo, basta levar a vida que todos levam:

Bris. Hui! Eu vou para o paraíso!

Diabo. E quem te disse a ti isso?

Bris. Lá hei-de ir desta maré.

Eu sou ũa mártir tal,

Açoites tenho eu levados

E tormentos suportados

Que ninguém me foi igual.

Se eu fosse ao fogo infernal

Lá iria todo o mundo!

Sendo Brísida, assim como o Frade, o Parvo, o Diabo e o Anjo, figuras do poeta na tessitura do mito do auto, seu pensamento, e dessa maneira seus caracteres e suas ações buscam lugares que dizem da poesia, do fazer poético, no caso, o riso e a ironia que se perfazem pela inversão da essência: a aparência. Em outra possibilidade, essas figuras são protagonistas, uma vez que falam da própria poesia; suas entradas e saídas seriam a própria voz do poeta falando de sua poesia, como o poeta dos Lusíadas que em outra dimensão diz de sua epopeia ao mesmo tempo em que a tece. Podemos falar que o poeta, ou os vários corpos de poeta presentes no Auto da barca do inferno, é partícipe de uma leitura da poética aristotélica em que a possibilidade da poesia apenas se evidencia enquanto é feita, no entanto sua feitura apenas se evidencia enquanto a ela se assiste como espectador, como leitor, como corpo presente e participante do corpo que se apresenta.

Das personagens que seguem a entrada de Brísida, não que sejam desimportantes para o mito do auto, respondem a uma necessidade de confirmação deste mesmo mito, o jogo de aparências dentro da essência: o judeu que é a aparência anterior do cristão, segundo uma interpretação da exegese cristã; ou o corregedor e o procurador, com o seu latim macarrônico, ironizado pelo Diabo, que são aparências, reminiscências mesmo de um Império Romano há 
muito decaído e apenas aparente em reinos como o de Portugal. Essas duas figuras do Direito anunciam a figura máxima deste desconcerto que é Enforcado, cujo martírio, insígnia muito maior que a de Brísida e por assim dizer, melhor alívio das culpas da vida material. O que fica é, se nem os oficiais da Igreja muito menos os oficiais do Direito cumprem com a essência de deus deveres, mas apenas em aparência, de nada vale ser sentenciado à forca para remissão de culpas e pecados, pois o enforcamento torna-se martírio vão:

\section{Diabo: Falou-te no purgatório? \\ Enforc. Diz que foi o Limoeiro, E ora por ele o salteiro E o pregão vitatório; E que era muito notório Que aqueles disciplinados Eram horas dos finados E missa de São Gregório.}

O que se pode, então dizer, diante da interpretação que se propõe do mito do Auto da barca do inferno, assim como interpretamos a figura do Parvo, das figuras dos cavaleiros, final desta cena ${ }^{5}$ ? Por que nesta apresentação das personagens umas pelas outras são os únicos que embarcam junto ao Parvo na Barca da Glória? O que se pode responder é que são de todas as figuras que se apresentam diante das barcas, as mais voláteis, as mais esfumaçadas e menos presentes e desta forma menos alegóricas, menos corporais, ou melhor, mais essenciais do que aparentes. Estes cavaleiros são mais ideais que o fidalgo ou frade, que podemos dizer são mais materiais; ou mártires no sentido que Brísida Vaz ironiza em suas falas. Estes cavaleiros são a própria memória, lugares da poesia de onde o poeta saca para compor seu auto. Desse modo, como cantam, estão fora da vida e apenas estando fora da vida, da conveniência do mundo, como

5 Assim como está anunciado no argumento do auto, em seu início, ao final a rubrica confirma "E assim embarcam./ Aqui fenece a primeira cena". 
também vive o Parvo, para não vivê-la em toda sua aparência, como vivem todos os outros passageiros da barca do inferno:

\author{
À barca, à barca segura! \\ Guardar da barca perdida! \\ À barca, à barca da vida! \\ Senhores, que trabalhais \\ Pela vida transitória, \\ Memória, por Deus, memória \\ Deste temeroso cais! \\ À barca, à barca, mortais! \\ Porém, na vida perdida \\ Se perde a barca da vida.
}

O que se percebe, dentro de uma possibilidade interpretativa, na cantiga dos cavaleiros, quando passam diante do "batel dos danados" é quase uma espécie de melancolia, exatamente por se denominar "barca da vida" e não "barca da glória", como sempre afirmam as rubricas, uma espécie de ambiguidade ("Porém, na vida perdida/Se perde a barca da vida”), pois tais cavaleiros estiveram o tempo todo fora do barco da vida, ou seja, fora da vida, não viveram, o que se confirma mais adiante quando um dos cavaleiros responde à perplexidade do Diabo diante do quadro: "Sequer conhecei-nos bem:/morremos nas partes de além,/e não queirais saber mais". Então o que se considera barco do inferno, uma vez que tudo é do avesso, aparente, é o barco da vida, o mundo mais corpo do que nunca, como diz Brísida Vaz, ao dizer que se ela for ao inferno "lá iria todo o mundo!" Assim, os cavaleiros, os iguais a si que o Anjo, desde a aparição do Parvo, aguardava, seriam ideia, todo o mais, uma vez, dentro do barco da vida, é corpo.

Portanto, é preferível para textos poéticos como este uma leitura que atente para as dobraduras e envergaduras do corpo do texto, escrutinando mesmo o fazer do poeta e assim do ator, como se para além das inflexões dramáticas, pelas intenções maliciosas, os acentos complacentes, pudesse-se alcançar o grão da voz. (BARTHES, 
2006, p.77), que, como afirma Ricoeur, seria o espectador esperado pela Poética e, "melhor ainda, o leitor ideal: sua inteligência, suas emoções "depuradas", seu prazer, na junção da obra e da cultura que esta cria"(1995, p.84).

\section{BIBLIOGRAFIA CITADA:}

ARISTÓTELES. Poética. Tradução, comentários e índices analítico e onomástico de Eudoro de Souza. São Paulo, Abril Cultural, 1973.

Retórica. Tradução e notas de Manuel Alexandre Júnior, Paulo

Famhouse Alberto e Abel do Nascimento Pena. Lisboa, Imprensa Nacional-Casa da Moeda, 1998.

AUERBACH. Figura. Tradução de Duda Machado. São Paulo, Ática, 1997.

BARTHES, Roland. O pražer do texto. Tradução de J. Guinsburg. $4^{\text {a }}$. ed. São Paulo, Perspectiva, 2006.

CÍCERO. De inventione. De L'invention. Texte étabil e traduit par G. Achard. Paris, Les Belles Letre, 1994.

CURTIUS, Ernst Robert. Literatura europeia e Idade Media latina. Tradução Teodoro Cabral e Paulo Rónai. São Paulo, Editora Hucitec; Editora da Universidade de São Paulo, 1996.

FOUCAULT, Michel. As palavras e as coisas: uma arqueologia das ciências bumanas. Tradução Salma Tannus Muchail. 9ª ed. São Paulo, Martins Fontes, 2007.

HANSEN, João Adolfo. Alegoria: construção e interpretação da metáfora. 2. ed. São Paulo, Atual, 1987.

PALLA, Maria José. Do essencial e do supérfluo. Estudo lexical do traje e adornos em Gil Vicente. Lisboa, Editorial Estampa, 1997.

RECKERT, Stephen. Gil Vicente: espiritu y letra. Madrid, Editorial Gredos, 1977.

RICOEUR, Paul. A metáfora viva. Tradução Dion Davi Macedo. São Paulo, Edições Loyola, 2000.

Tempo e narrativa. Tradução Constança Marcondes Cesar. Campinas, Papirus, 1995, tomo I.

SILVA, Jaqueson Luiz. Santo Agostinho: poética e retórica. Intersecções. Revista de estudos sobre práticas discursivas e textuais, v.1, p. 1-8, 2008.

TEYSSIER, Paul. Gil Vicente - o autor e a obra. Lisboa, ICLP/MEU, 1982.

VICENTE, Gil. Auto da barca do inferno in SPINA, Segismundo (org.). Obras do teatro vicentino. 4. ed. São Paulo, DIFEL, 1983.

YATES, Frances. A arte a memória. Tradução Flavia Blancher. Campinas, Editora da Unicamp, 2007.

Résumé : Malgré la problématique historico-littéraire qui implique les origines du théâtre vicentin, ainsi que sa filiation à une présomption théâtrale allégorique et de caractère théologique et moral, cette étude vise à trouver dans le texte de l'acte de la barque de l'enfer (Auto da barca do inferno) quelques indications rhétorico-poétiques de la mémoire et de l'action présentes dans l'oeuvre du poète et le corps de l'acteur. 
Mots-clefs : poétique ; rhétorique ; Gil Vicente ; acte ; allégorie 